This item was submitted to Loughborough's Research Repository by the author.

Items in Figshare are protected by copyright, with all rights reserved, unless otherwise indicated.

\title{
The state of the art in selective catalytic reduction control
}

\section{PLEASE CITE THE PUBLISHED VERSION}

https://doi.org/10.4271/2014-01-1533

\section{PUBLISHER}

(C) SAE International

\section{VERSION}

AM (Accepted Manuscript)

\section{PUBLISHER STATEMENT}

Copyright (C) 2014 SAE International. This paper is posted on this site with permission from SAE International. It may not be shared, downloaded, transmitted in any manner, or stored on any additional repositories or retrieval system without prior written permission from SAE.

\section{LICENCE}

All Rights Reserved

\section{REPOSITORY RECORD}

Skaf, Zakwan, Timur Aliyev, Leo Shead, and Thomas Steffen. 2015. "The State of the Art in Selective Catalytic Reduction Control". figshare. https://hdl.handle.net/2134/17381. 


\title{
The State of the Art in Selective Catalytic Reduction Control
}

\author{
Zakwan Skaf ${ }^{1}$, Timur Aliyev ${ }^{2}$, Leo Shead ${ }^{2}$, Thomas Steffen ${ }^{1}$ \\ 1 Loughborough University, 2 Caterpillar
}

Copyright @ 2014 SAE International

\begin{abstract}
Selective Catalytic Reduction (SCR) is a leading aftertreatment technology for the removal of nitrogen oxide $\left(N \mathrm{~N}_{\mathrm{x}}\right)$ from exhaust gases (DeNOx). It presents an interesting control challenge, especially at high conversion, because both reagents $\left(\mathrm{NO}_{x}\right.$ and ammonia) are toxic, and therefore an excess of either is highly undesirable.

Numerous system layouts and control methods have been developed for SCR systems, driven by the need to meet future emission standards. This paper summarizes the current stateof-the-art control methods for the SCR aftertreatment systems, and provides a structured and comprehensive overview of the research on SCR control. The existing control techniques fall into three main categories: traditional SCR control methods, model-based SCR control methods, and advanced SCR control methods. For each category, the basic control technique is defined. Further techniques in the same category are then explained and appreciated for their relative advantages and disadvantages.
\end{abstract}

Thus this paper presents a snapshot of the current state of the art for the research area of SCR control. This is a very active field, and it is hoped that by providing a better understanding of the different control strategies already developed for SCR control, future areas of interest will be identified and developed with the ultimate aim of satisfying the increasingly stringent emissions legislation.

\section{INTRODUCTION}

\section{Overview of SCR}

SCR catalysts remove nitrogen oxides ( $\mathrm{NO}_{\mathrm{x}}$ ) through a reaction with a reducing agent, which is typically ammonia $\left(\mathrm{NH}_{3}\right)$. A catalyst is required to speed up this reduction reaction, thus reducing the amount of harmful $\mathrm{NO}_{x}$ emissions significantly. Urea-based SCR catalysts use aqueous urea that is injected into the exhaust stream to produce $\mathrm{NH}_{3}$ as the active $\mathrm{NO}_{x}$ reducing agent. Typically, an aqueous solution of diesel emissions fluid (DEF) with $32.5 \%$ urea content is carried on board of a vehicle. This concentration has the lowest freezing temperature (eutectic mixing ratio), so even a partially frozen tank maintains the same concentration. An injection system is used to supply it into the exhaust gas stream entering the SCR catalyst, where it decomposes into gaseous $\mathrm{NH}_{3}$ and can be stored in the catalyst. The $\mathrm{NO}_{x}$ contained in the engine exhaust gas then reacts with the stored $\mathrm{NH}_{3}$, which produces nitrogen and water. The amount of urea injected is controlled to provide a high $\mathrm{NO}_{x}$ conversion whilst keeping the emissions of excess $\mathrm{NH}_{3}$ (slip) to low values. Both demands are conflicting targets, because higher concentrations of $\mathrm{NH}_{3}$ lead to better conversion, but also increased slip. At high conversion, the margin for error is very small, which makes the precise control of $\mathrm{NH}_{3}$ dosing technically challenging. An Ammonia Oxidation Catalyst (AOC) can be used after the SCR catalyst to reduce $\mathrm{NH}_{3}$ emissions. While this increases the tolerance to overdosing errors, it only works well at high temperatures, and it may lead to the production of unwanted Nitrous Oxide $\left(\mathrm{N}_{2} \mathrm{O}\right)$.

SCR catalysts first appeared on heavy-duty stationary engines where high $\mathrm{NO}_{x}$ levels are present and where steady state duty cycles can be considered to be the main operating conditions. Under these conditions, reasonable conversion can be achieved using open loop SCR control with fixed $\mathrm{NH}_{3}$ to $\mathrm{NO}_{x}$ ratio (ANR). Applying this simple approach to a vehicle, where transient conditions are more frequent, is more challenging, and requires specific transient corrections.

\section{SCR Configurations}

A typical Diesel or lean burn engine aftertreatment system consists of a Diesel Oxidation Catalyst (DOC), a Diesel Particulate Filter (DPF), a urea SCR catalyst, and an optional Ammonia Oxidation Catalyst (AOC). The DOC, DPF, and SCR can be combined in a variety of exhaust system configurations [1]. The DOC is usually placed first, to benefit from the hot engine exhaust, [2]. The SCR can be either in front of or behind the DOC catalyst. Both layouts have advantages for different applications. For instance, [3] show a typical set-up where the SCR system is downstream of the DOC/DPF system (Figure 1). This order has the advantage that the DOC can reform $\mathrm{NO}$ into $\mathrm{NO}_{2}$, which makes the $\mathrm{NO}_{x}$ conversion in the SCR system more effective.

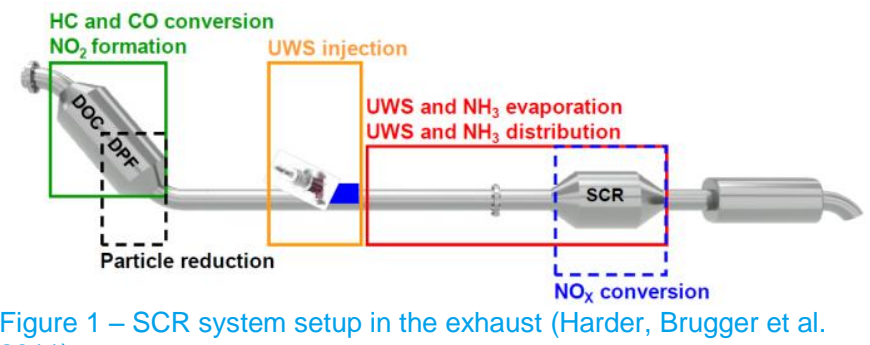
2011) 


\begin{tabular}{|c|c|c|}
\hline Ser. & Chemical Reaction & Reaction Rate Expression \\
\hline$(1)$ & $\mathbf{S}+\mathbf{N H}_{3} \rightarrow\left(\mathrm{NH}_{3}\right)_{\mathrm{S}}$ & $\dot{r}_{1}=k_{1} e^{\left[\frac{-E_{1}}{R_{u} T_{W}}\right]} C_{\mathrm{NH}_{3}}(1-\theta)$ \\
\hline$(2)$ & $\left(\mathrm{NH}_{3}\right)_{\mathrm{S}} \rightarrow \mathrm{S}+\mathrm{NH}_{3}$ & $\left.\dot{r}_{2}=k_{2} e^{\left[\frac{-E_{2}\left(1-\alpha_{\theta} \theta\right)}{R_{u} T_{W}}\right]}\right]_{\theta}$ \\
\hline (3) & $2\left(\mathrm{NH}_{3}\right)_{\mathrm{S}}+\mathrm{NO}+\mathbf{N O}_{2} \rightarrow 2 \mathrm{~N}_{2}+3 \mathrm{H}_{2} \mathrm{O}+2 \mathrm{~S}$ & $\dot{r}_{3}=k_{3} e^{\left[\frac{-E_{3}}{R_{u} T W}\right]} \theta C_{\mathrm{NO}} C_{\mathrm{NO}_{2}}$ \\
\hline$(4)$ & $4\left(\mathrm{NH}_{3}\right)_{\mathrm{s}}+4 \mathrm{NO}+\mathrm{O}_{2} \rightarrow 4 \mathrm{~N}_{2}+6 \mathrm{H}_{2} \mathrm{O}+4 \mathrm{~S}$ & $\dot{r}_{4}=k_{4} e^{\left[\frac{-E_{4}}{R_{u} T_{W}}\right]} \theta C_{\mathrm{NO}}\left(C_{\mathrm{O}_{2}}\right)^{\beta}$ \\
\hline$(5)$ & $4\left(\mathrm{NH}_{3}\right)_{\mathrm{S}}+3 \mathrm{NO}_{2} \rightarrow 3.5 \mathrm{~N}_{2}+6 \mathrm{H}_{2} \mathrm{O}+4 \mathrm{~S}$ & $\dot{r}_{5}=k_{5} e^{\left[\frac{-E_{5}}{R_{u} T}\right]} \theta C_{\mathrm{NO}_{2}}$ \\
\hline$(6)$ & $2\left(\mathrm{NH}_{3}\right)_{S}+1.5 \mathrm{O}_{2} \rightarrow \mathrm{N}_{2}+3 \mathrm{H}_{2} \mathrm{O}+2 \mathrm{~S}$ & $\dot{r}_{6}=k_{6} e^{\left[\frac{-E_{6}}{R_{u} T_{W}}\right]} \theta C_{\mathrm{O}_{2}}$ \\
\hline$(7)$ & $\mathrm{NO}+\mathbf{0 . 5 \mathbf { 5 O } _ { 2 }} \leftrightarrow \mathrm{NO}_{2}$ & $\dot{r}_{7}=k_{7} e^{\left[\frac{-E_{7}}{R_{u} T_{W}}\right]}\left[C_{\mathrm{NO}_{2}}\left(C_{\mathrm{O}_{2}}\right)^{0.5}-\frac{C_{\mathrm{NO}_{2}}}{K_{C}}\right]$ \\
\hline (8) & $2\left(\mathrm{NH}_{3}\right)_{\mathrm{S}}+2 \mathrm{NO}_{2} \rightarrow \mathrm{N}_{2}+\mathrm{N}_{2} \mathrm{O}+3 \mathrm{H}_{2} \mathrm{O}+2 \mathrm{~S}$ & $\dot{r}_{8}=k_{8} e^{\left[\frac{-E_{8}}{R_{u} T}\right]} \theta C_{\mathrm{NO}_{2}}$ \\
\hline
\end{tabular}

However, putting the SCR before the DPF helps to avoid fuel economy losses from diesel engines [2], and may help to mitigate deposit formation. Alternative configurations of aftertreatment devices in the exhaust line are possible. In [4-7], the integration of DPF and SCR catalysts in one place is proposed to reduce system size. The inclusion of a $\mathrm{NO}_{x}$ trap [5] before the SCR system can significantly improve cold start behavior by capturing the $\mathrm{NO}_{\mathrm{x}}$ and releasing it when the SCR system is operational. The addition of an Ammonia Oxidation Catalyst (AOC) or Ammonia Slip Catalyst (ASC) after the SCR system is able to reduce the release of $\mathrm{NH}_{3}$ into the environment [6]. This also allows running the SCR catalyst with excess ammonia to increase the conversion [8]. The on-board generation of $\mathrm{NH}_{3}$ is considered to avoid the use of urea [7] mostly for practical reasons.

\section{Issues in SCR Controls}

Control and control-related tasks in SCR systems have to satisfy a number of concerns. Keeping below the emission limits is essential, but so is the avoidance of damage to the system via deposits or excessive temperatures.

The key challenges of the SCR control system can be summarized as:

- cross sensitivity of $\mathrm{NO}_{x}$ sensors to $\mathrm{NH}_{3}$,

- high nonlinearities in the chemical reaction rates, and

- a combination of short, medium and very long time scales in one system.

Most SCR control strategies generally involve a combination of open-loop and closed-loop control. Both output feedback (based on sensors only) and state feedback (using a model based state estimate) are being used.

\section{MODEL}

In order to facilitate an effective control strategy, a model of an SCR system has to capture the key characteristics of the system, without being too complex to evaluate or to calibrate.

\section{Reaction Kinetics}

Following the Eley-Rideal mechanism, there are 8 main chemical reactions representing the relevant dynamics in the catalytic converter as detailed in Table 1 . The reagents that are rate limiting according to the reaction rate model are set in bold (note that even if several molecules of the same species are converted, typically only the first one is rate limiting).

In these reactions, $\mathrm{NH}_{3}$ refers to gaseous $\mathrm{NH}_{3}$ (in the gas phase). S refers to an unoccupied active catalytic site, and $\left(\mathrm{NH}_{3}\right)_{\mathrm{S}}$ refers to an $\mathrm{NH}_{3}$ molecule adsorbed at such a site (in the solid phase). Only such an absorbed $\mathrm{NH}_{3}$ molecule $\left(\mathrm{NH}_{3}\right)_{\mathrm{S}}$ is activated and therefore available for chemical reactions $(3-5$, 8) with $\mathrm{NO}_{\mathrm{x}}$.

The first two reactions in Table 1 are the adsorption and desorption of $\mathrm{NH}_{3}$ with the catalyst surface - these determine the equilibrium coverage of the catalyst.

Then there are three selective catalytic reactions (3-5) (highlighted in Table 2) with distinct stoichiometry and kinetics. They all break down $\mathrm{NO}_{x}$ using the associated $\mathrm{NH}_{3}$, and the relative speed depends on the ratio between NO:NO2. The first of these reactions (3) is called the fast SCR reaction, which requires both $\mathrm{NO}$ and $\mathrm{NO}_{2}$ to be present, and which is most effective at $\mathrm{NO}: \mathrm{NO}_{2}$ ratios close to 1 . Any excess $\mathrm{NO}$ feeds the second, slower reaction (4), which is often considered the standard SCR reaction. Excess $\mathrm{NO}_{2}$ gets converted via the third reaction (5), which is typically even slower than the standard reaction. 
The sixth reaction in Table 1 is the oxidation of surface $\mathrm{NH}_{3}$, which leads to a loss of $\mathrm{NH}_{3}$. The seventh reaction is the oxidation of nitric oxide (NO) into nitrogen dioxide $\left(\mathrm{NO}_{2}\right)$, which is not a relevant reaction in most SCR catalysts, but it does occur at significant rates in an oxidation catalyst.

There is a further reaction (8) for $\mathrm{NO}_{2}$, which is the primary source of $\mathrm{N}_{2} \mathrm{O}$. Due to the low reaction rate this is not typically relevant for the $\mathrm{NO}_{2}$ balance, but it is essential if $\mathrm{N}_{2} \mathrm{O}$ emissions have to be modelled.

As an alternative to the Arrhenius kinetics, [9] proposes to use the sticking equation to model the adsorption reaction. It is based on a stochastic model of locality alone without reference to activation energy, leading to a slightly different model of the dynamics.

Table 2 - Key SCR Reactions

\begin{tabular}{|l|l|l|l|l|}
\hline Ser. & Ammonia & Nitrogen Oxides & $\begin{array}{l}\text { Ratio } \\
\mathrm{NH3}: \mathrm{NOx}\end{array}$ & Name \\
\hline$(3)$ & $2 \mathrm{NH}_{3}$ & $2\left(1 \mathrm{NO}+1 \mathrm{NO}_{2}\right)$ & $1: 1$ & Fast SCR \\
\hline$(4)$ & $4 \mathrm{NH}_{3}$ & $4 \mathrm{NO}$ & $1: 1$ & Standard SCR \\
\hline$(5)$ & $4 \mathrm{NH}_{3}$ & $3 \mathrm{NO}_{2}$ & $4: 3$ & $\mathrm{NO}_{2} \mathrm{SCR}$ \\
\hline
\end{tabular}

\section{Time Scales}

The relevant effects of the SCR system happen on very different time scales, and from a control point of view it can be very helpful to separate them. An overview of the different effects is shown in Table 3, and a structured block diagram can be found in Figure 2. The fastest time scale is the transport and reaction in the gas phase, which typically only takes fractions of a second.

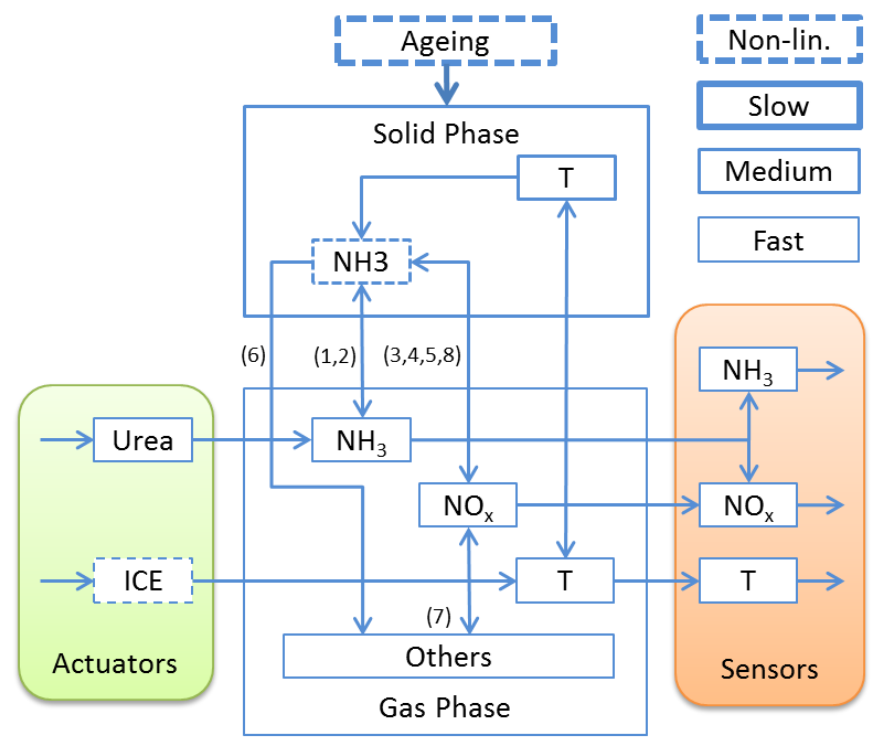

Figure 2 - Block diagram with signals and time scales

The medium time scale concerns the catalyst states: temperature and $\mathrm{NH}_{3}$ coverage. Both typically change in the order of minutes, and this dynamic can be shaped using control within reasonable boundaries [10].
Finally the ageing and poisoning of the system happens over hundreds of hours. Poisoning can be partially reversed using regeneration cycles, while ageing is typically a one way process. An example for tracking these processes is given in [11].

Table 3 - System Time Scales

\begin{tabular}{|c|c|c|c|}
\hline $\begin{array}{l}\text { Time } \\
\text { Scale }\end{array}$ & $<$ seconds & Ca 1-10 min. & Days to years \\
\hline Name & Quasi stationary & Short term & Long term \\
\hline Effects & $\begin{array}{l}\text { Gas phase } \\
\text { Gas transport } \\
\mathrm{NO}_{x} \text { dynamics } \\
\mathrm{NH}_{3} \text { adsorption } \\
\text { Engine transients } \\
\text { Actuator response: } \\
\text { Urea dosing } \\
\text { Sensor response: } \\
\mathrm{NO}_{x} \text {, temperature, flow }\end{array}$ & $\begin{array}{l}\mathrm{NH}_{3} \text { coverage } \\
\text { dynamics } \\
\text { Substrate } \\
\text { temperature } \\
\text { dynamics }\end{array}$ & $\begin{array}{l}\text { Sensor drift } \\
\text { Actuator drift } \\
\text { Catalyst aging } \\
\text { Urea quality } \\
\text { variations }\end{array}$ \\
\hline Relevance & $\begin{array}{l}\text { Uncontrollable quasi- } \\
\text { stationary modelling is } \\
\text { sufficient }\end{array}$ & $\begin{array}{l}\text { SCR control, } \\
\text { Thermal } \\
\text { management }\end{array}$ & $\begin{array}{l}\text { Through life } \\
\text { performance }\end{array}$ \\
\hline
\end{tabular}

\section{Nonlinearities}

The SCR model typically exhibits strong nonlinearities, which originates from the reaction kinetics of the chemical reactions. This means that the behavior of the model is highly dependent on the system operating point. It is tempting to linearize the model, and to use fixed gain or gain scheduled linear controllers designed for specific operating points. However, this can lead to a significant loss of accuracy, and it can prevent the system from reaching the best possible $\mathrm{NO}_{\mathrm{x}}$ conversion over a wide range of operating conditions.

A very prominent nonlinearity appears due to the crosssensitivity of the $\mathrm{NO}_{x}$ sensor to $\mathrm{NH}_{3}$. This leads to an ambiguity, because elevated sensor readings could indicate excess $\mathrm{NO}_{x}$ or excess $\mathrm{NH}_{3}$. In extreme cases, this can destabilize the control system [12]. The use of an $\mathrm{NH}_{3}$ sensor can help to avoid this ambiguity, because the $\mathrm{NH}_{3}$ sensor is not sensitive to $\mathrm{NO}$ [13] (although there is an issue with high $\mathrm{NO}_{2}$ levels). From a control point of view, neither a perfect $\mathrm{NO}_{\mathrm{x}}$ sensor nor a perfect $\mathrm{NH}_{3}$ are currently available.

The most important nonlinearity is dependent on the temperature of the catalyst. The interaction between the different reactions means that SCR catalysts are only efficient within a certain temperature window. The exact temperature limits depend on the catalyst technology and parameters, but the general shape is surprisingly little affected, as shown in Figure 3. At low temperatures, conversion is insufficient because the reaction rates are low (and injection may not be possible due to potential deposits). At higher temperatures, desorption is so fast that it becomes impossible to maintain sufficient $\mathrm{NH}_{3}$ coverage without excessive $\mathrm{NH}_{3}$ emissions [14]. 


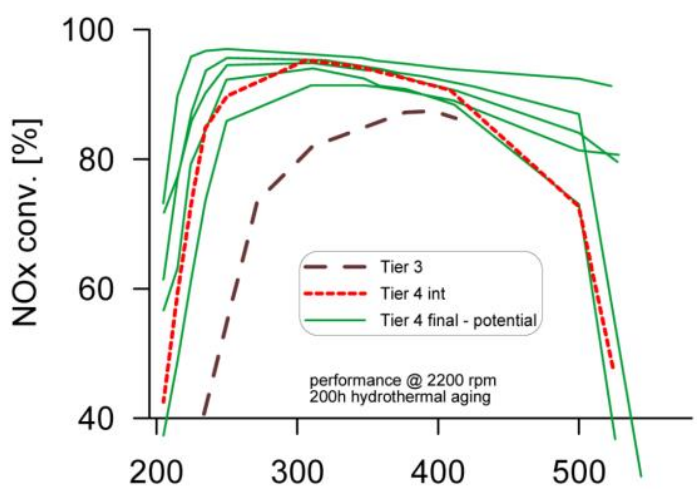

Figure 3 - Conversion over Temperature [15]

Finally, the system performance is not only dependent on the temperature, but also on the flow rate (or space velocity), as pointed out by [16].

\section{CONTROL METHODS}

The traditional control methods of SCR systems are considered first, followed by typical modern control methods. The review then proceeds to advanced experimental methods, which have been developed to meet expected future vehicle emissions legislation.

\section{Traditional SCR Control Methods}

The following section presents an overview of research within the field of traditional SCR control methods.

\section{Open Loop Control}

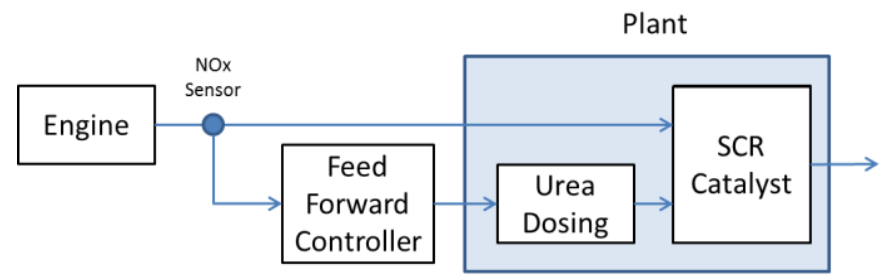

Figure 4 - Open Loop Control Structure

The principle of the open loop control strategy is simple and based on calculation of the required amount of urea as a fraction of the estimated or measured $\mathrm{NO}_{x}$ content in the exhaust gas, and it is provided via a urea injector (see Figure 4). Due to the nature of open-loop control, it cannot compensate for measurement errors, which means that errors in the required $\mathrm{NH}_{3}$ dosage will accumulate in the catalyst and eventually lead to higher $\mathrm{NO}_{x}$ or higher $\mathrm{NH}_{3}$ emissions of the same order as the measurement error.

Still, open-loop approaches have proven to be sufficient to meet Euro-4 and Euro-5 emission standards [17], with a conversion of $60 \%-80 \%$ [18] being easily achievable. If operating conditions change only slowly, open-loop controllers are an especially suitable solution to the SCR control design problem [16].

Page 4 of 12
On the other hand, the study in [17] suggests that open-loop control cannot handle engine transient exhaust gas conditions well, because the delay caused by the $\mathrm{NH}_{3}$ storage in the system is not considered. Therefore, rapidly changing conditions necessitate the use of advanced closed-loop SCR control techniques.

\section{Conventional PID Control}

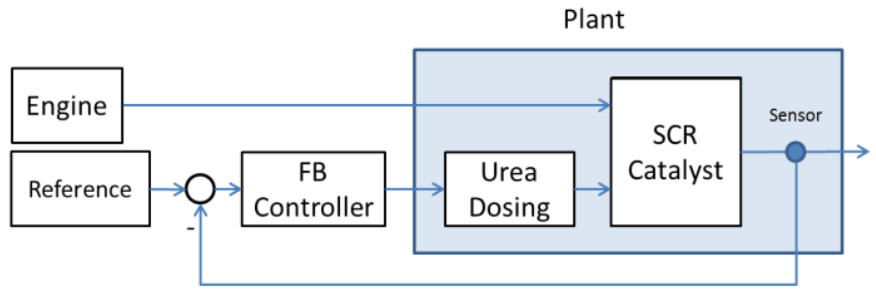

Figure 5 - Output Feedback Control Structure

Conventional controllers can be seen in most control systems of SCR aftertreatment. They typically follow an output feedback approach (see Figure 5), which can be combined with an additional feedforward branch. A typical sensor/actuator pair would be NOx conversion to ammonia dosing, as direct control of the tailpipe NOx concentration is not an appropriate control problem.

Although the results show that it works as expected, the output feedback approach is not entirely convincing from a theoretical perspective. Because ammonia slip causes a sign reversal, the control loop can easily become unstable at high conversion or when an excess of ammonia is present in the catalyst. The basic control structure is only stable and feasible at low conversion where $\mathrm{NH}_{3}$ slip is rare. Even with gain scheduling, the control remains fragile, as shown by [16].

To avoid this, an accurate way of slip detection is required, for example using a model of the SCR system. This causes additional complexity similar to model based control, without providing the benefits expected of modern systems in terms of clear structure and model-based design. There are examples of early attempts to combine classical PI control with a modelbased approach, such as [18]. The benefit of this latter approach compared to a modern, observer based, approach is in its reduced complexity, but this also means that the performance is less than ideal.

Alternatively, a nonlinear model of an SCR system can be used together with a PID control scheme with $\mathrm{NH}_{3}$ slip detection [19]. Further examples of PI/PID control techniques that have been used in SCR control are shown in Table 4, along with their references. 
$[19,24]$ proposed a model-based control system for SCR urea dosing that employed an embedded real-time SCR model and an $\mathrm{NH}_{3}$ sensor. Furthermore, [19] demonstrated the potential of an $\mathrm{NH}_{3}$ sensor for on-board diagnostics. Instead of an actual $\mathrm{NH}_{3}$ sensor, a model can be used for determining reaction rates and $\mathrm{NH}_{3}$ emissions. However, it is to be expected that this kind of forward simulation model is rather sensitive to disturbances and the accumulation of model errors.

A patent [25] proposes the use of a test signal ("wiggle test") to determine the differential response of the $\mathrm{NO}_{x}$ sensor to changes in urea dosing. The change in response can be used to resolve the sensor ambiguity and therefore to distinguish $\mathrm{NH}_{3}$ slip conditions from low $\mathrm{NO}_{x}$ conversion. However, this approach is limited to steady-state operation, otherwise the effect of $\mathrm{NO}_{x}$ volatility tends to dominant the slow response to urea dosing.

\section{Model-Based SCR Control Methods}

\section{Slip Detection}

$\mathrm{NH}_{3}$ slip is the amount of $\mathrm{NH}_{3}$ released at the catalyst tailpipe. This can happen due to over-dosage of $\mathrm{NH}_{3}$ beyond the capacity of the catalyst, or due to the faster desorption at higher temperatures. This has three negative effects:

- it causes potentially harmful emissions,

- it causes the loss of ammonia for the SCR reaction,

- and it can also lead to erroneous readings from the $\mathrm{NO}_{x}$ sensor due to cross sensitivity to $\mathrm{NH}_{3}$.

The cross sensitivity can cause a sign reversal in the system response, which can render classical control unstable.

A typical extension of classical control is therefore a separate slip detection function, which will identify a situation of excess tailpipe $\mathrm{NH}_{3}$ and reset the system by stopping urea dosing for a period of time. There have been many studies focusing on the detection of $\mathrm{NH}_{3}$ slip [14,19,24-28]. They are typically modelbased, and may use sensor information to improve the accuracy of the detection. For example, a simple first order model is used for the $\mathrm{NH}_{3}$ slip in [14]. The $\mathrm{NH}_{3}$ slip model gets activated when the $\mathrm{NH}_{3}$ storage on the catalyst is around $95 \%$ to $100 \%$ full, although it is not clear whether this refers to percent coverage or another maximum level.

\section{State Feedback}

Typically, the main goals of a feedback controller are stability, reduced sensitivity to disturbances, and reduced effects of the most detrimental sources of error. Such errors can include inaccurate estimation of $\mathrm{NO}_{x}$ concentration, or a systematic error between desired and injected amounts of urea solution [18].

The dominant dynamics of the SCR system are based on the level of $\mathrm{NH}_{3}$ coverage on the SCR catalyst. The influence of urea dosing on $\mathrm{NH}_{3}$ coverage is very direct, and therefore control loop stability not the main issue. The most difficult problem is how to establish the ammonia coverage in the catalyst, since it is not directly measurable, model parameters have significant uncertainties, and state estimation is only effective in some operating conditions. Another challenging problem is to define and track the optimal operating point, which has to simultaneously provide both high $\mathrm{NO}_{x}$ conversion and minimal $\mathrm{NH}_{3}$ slip.

Table 5 - Potential control variables

\begin{tabular}{|c|c|c|c|c|c|}
\hline Variable & Source & Control Dynamics & \begin{tabular}{|l} 
Disturbance \\
Dynamics
\end{tabular} & Significance & Reference \\
\hline $\begin{array}{l}\mathrm{NH}_{3} \text { concentration } \\
\text { (gas) }\end{array}$ & $\begin{array}{l}\text { Fast state or } \\
\text { output }\end{array}$ & Minimal delay & Slow & System limit & Constant \\
\hline $\begin{array}{l}\mathrm{NO}_{x} \text { concentration } \\
\text { (gas) }\end{array}$ & $\begin{array}{l}\text { Fast state or } \\
\text { output }\end{array}$ & Complex & Fast & System goal & Mostly constant \\
\hline $\mathrm{NO}_{x}$ conversion & $\begin{array}{l}\text { Division of } \\
\text { outputs }\end{array}$ & Slow \& complex & Fast & Subsystem goal & Constant \\
\hline
\end{tabular}




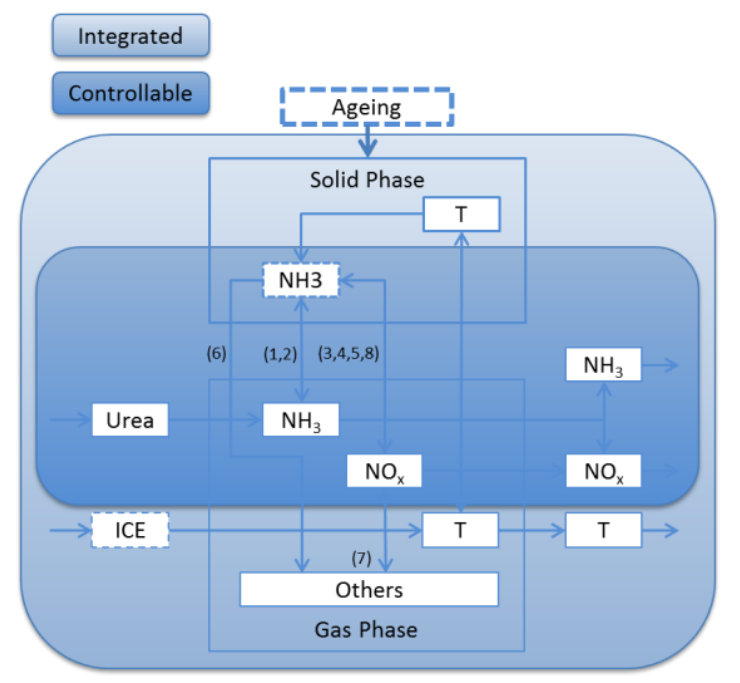

Figure 6 - Block diagram demonstrating the control influence of urea control only vs an integrated control scheme for urea, NOx and exhaust temperature

Another key choice is how to draw the boundaries of the control problem, as demonstrated in Figure 6 . Using only urea dosing as a control input leaves large parts of the system uncontrollable. Including the calibration of the air and fuel system of the Internal Combustion Engine (ICE) as a control input increases the control authority and range significantly, because exhaust NOx concentration and exhaust temperature offer additional control inputs in an integrated control scheme.

The choice of the control variables is important from this point of view. The seemingly obvious choice of controlling tailpipe $\mathrm{NO}_{x}$ concentrations turns out to be a poor choice from a control point of view, because it responds quickly to disturbances from the engine, but only slowly to changes in the control. It is therefore more effective to control the $\mathrm{NH}_{3}$ coverage, which leads to better and faster disturbance rejection. An overview of the key dynamics and variables is given in Table 5 . The choice of variable is also temperature dependent: at low temperature storage estimation is critical, but at high temperature storage is much lower, which can leads to challengingly fast system dynamics.

Most approaches in the literature use a nonlinear reference for the desired coverage, based on temperature and flow rate, and then apply linear state feedback control using urea dosing to achieve this level.

An extreme form of state feedback, the use of switching mode control, has been studied by [29]. They use a first order model for the dynamics of the SCR system, and extend the model with an integral weighting function, and then define a switching surface in this two-dimensional state space. Switching mode control works very well in this case because of the simple dynamics of the system. It delivers excellent suppression of disturbances and good robustness. However, it is not clear what the effect of the "all or nothing" input signal is on the urea dosing actuator. It may simplify the design, or it may cause problems by switching the injector on and off at high frequency. It could also create an increased risk of deposits and uneven distribution of ammonia across the catalyst.
State Estimation

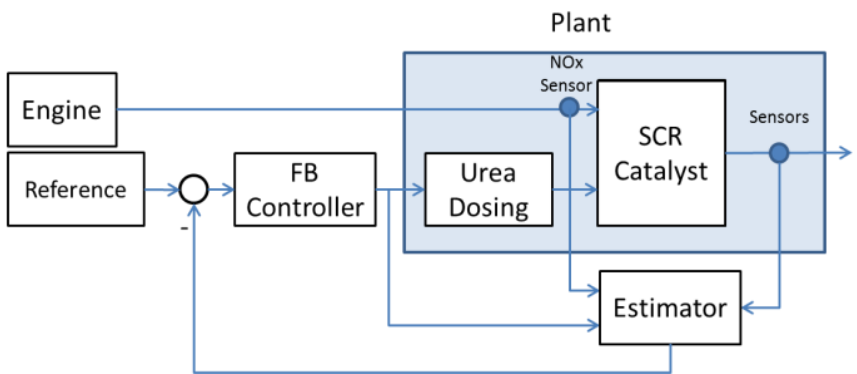

Figure 7 - State Estimation Feedback Control Structure The very limited measurement possibilities and the complexity of the involved chemical processes are critical issues that make control of SCR quite challenging. Therefore, there is a need to estimate the values of required variables for control design. The state estimate can then be used as an input for the controller as shown in Figure 7.

Many model-based approaches have appeared in the literature on state estimation in linear or linearized SCR systems [30,31]. The basic idea is to find a state estimate $\hat{x}$ using a parallel model and output feedback

$$
\dot{\hat{x}}=A \hat{x}+B u+L(y-C \hat{x})
$$

However, linear approaches are limited due to the presence of nonlinearities, parametric uncertainties and variable disturbances $[32,33]$. The use of sliding mode observers for state estimation can have some benefits in dealing with nonlinearities, disturbance and transient situations because of their robust characteristics with respect to state estimation. A sliding mode observer using a sliding mode state observer is presented by [32]. It is shown that the sliding mode observers are capable of detecting sensor faults effectively.

Recent papers have applied the extended Kalman filter (EKF) to the SCR problem [32-34]. The two key differences to the linear approach is that a system linearization around the current state estimate is being used, and that the optimal observer gain $L$ is calculated dynamically based on linearized model and current covariance. This increases the computational complexity significantly, and therefore it is feasible only for rather simple models

The paper [35] investigates three different outlet SCR sensor configurations, with two $\mathrm{NH}_{3}$ coverage states in each of 13 axial elements, and all reactions of Table 1 . In order to reduce computational burden, the authors of [34] take the $\mathrm{NH}_{3}, \mathrm{NO}$ and $\mathrm{NO}_{2}$ outlet concentrations and $\mathrm{NH}_{3}$ coverage as the states of a single element lumped-parameter model, neglecting modelling reactions $(5,6$, and 8$)$ of Table 1 , and compare the continuous-discrete EKF variant with an ordinary EKF. 
Table 6 - Examples of State Estimation techniques used in SCR systems

\begin{tabular}{|c|c|c|c|c|c|}
\hline Ref. & Year & Model & Observer & Goals & Results \\
\hline [35] & 2013 & Nonlinear & EKF & $\begin{array}{l}\text { Estimate internal species } \\
\text { concentration and storage states of } \\
\text { an SCR using } \mathrm{NO}_{x} \text { and } \mathrm{NH}_{3} \text { sensors }\end{array}$ & Simulations \\
\hline$[50]$ & 2010 & Nonlinear & LPV observer & $\begin{array}{l}\text { Estimate the catalyst } \mathrm{NH}_{3} \text { coverage } \\
\text { ratio }\end{array}$ & Simulations \\
\hline [32] & 2009 & Nonlinear & Sliding mode & $\begin{array}{l}\text { Estimate the catalyst } \mathrm{NH}_{3} \text { coverage } \\
\text { ratio }\end{array}$ & Simulation of FTP75 \\
\hline [31] & 2008 & Linear & $\begin{array}{l}\text { Linear estimator } \\
\text { / pole } \\
\text { placement }\end{array}$ & $\begin{array}{l}\text { Estimate the actual } \mathrm{NO}_{x} \\
\text { concentration \& catalyst } \mathrm{NH}_{3} \\
\text { coverage ratio }\end{array}$ & $\begin{array}{l}\text { An experimentally } \\
\text { validated, higher } \\
\text { order simulation }\end{array}$ \\
\hline
\end{tabular}

Estimation can also be used to cover the ageing state of the system. The approach in $[32,33]$ neglects the dynamics of the fast reaction (3) to simplify the model, and investigates the addition of a slowly time-varying $\mathrm{NH}_{3}$ storage capacity state to the model for estimating ageing effects. The separation into nominal dynamics and ageing dynamics is shown in Figure 5.

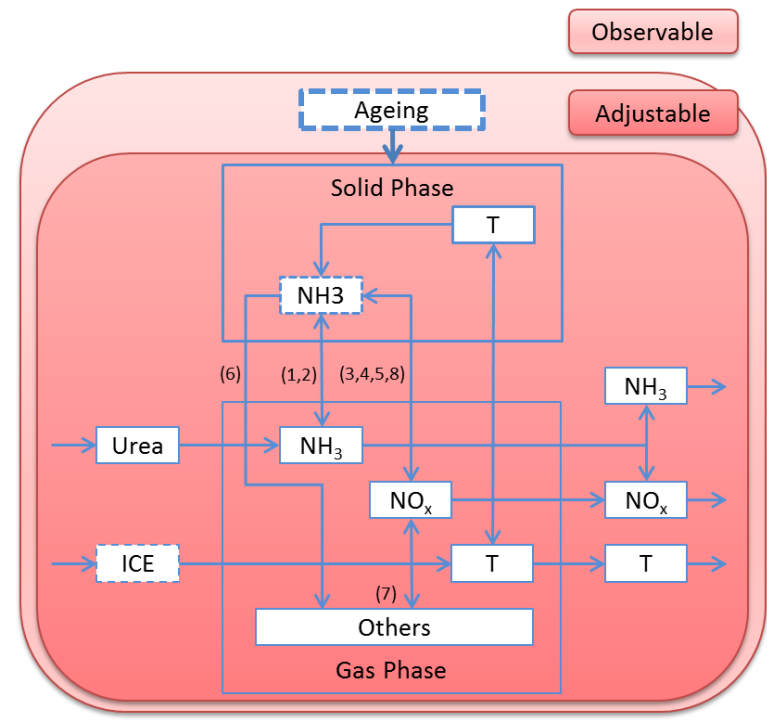

Figure 8 - Observability check: using tailpipe sensors, the whole system is observable, but only a part of it is controllable

EKF estimation performance is generally very good in all of these studies. It is a natural choice for combination with advanced control methods, both benefitting from the development of a high-fidelity, computationally efficient, control-oriented model. The availability of analytical Jacobians of the non-linear model also helps with convenient implementation.

Page 7 of 12
In summary, the most relevant state estimation techniques used in SCR systems are shown in Table 6 [11,30-36].

\section{Advanced SCR Control Methods}

While modern control is very successful at maintaining the right $\mathrm{NH}_{3}$ coverage, it fails to achieve optimal operation of the SCR system within the context of other systems as discussed above. For a more comprehensive approach, advanced control methods are being considered, that often include an element of online optimization. This allows compromises to be made between conflicting demands such as urea consumption, system degradation and efficiency. In the following sections, an overview of the research within the field of advanced SCR control methods will be given.

\section{Model-Based Predictive Control (MPC)}

Progressively increasing constraints and conflicting control objectives of SCR aftertreatment systems make advanced control techniques such as model-based predictive control (MPC) attractive, and the improved computing power of today's processors means that its implementation is becoming practical $[37,38]$. The nature of MPC makes this method a logical next step in the evolution of SCR control technology over other available techniques presented in this review.

The research by [39] is the first example of the use of MPC for an SCR system. Their MPC is based on a first-order lineartime-varying approximation of an embedded fourth-order nonlinear model. They chose to use an infinite prediction horizon using a terminal cost term to guarantee stability, and a control horizon fixed at three. The cost function consists of two parts: the output $\mathrm{NO}_{x}$ inefficiency tracking error term, and the input ANR increment penalty term. Furthermore, the MPC algorithm uses feedback from $\mathrm{NO}_{x}$ and $\mathrm{NH}_{3}$ catalyst outlet sensors. Significant simplifications to avoid on-line computational effort included omission of a constrained optimization in favor of a heuristic back-off saturation law 
approach in order to satisfy the slip constraint. Additionally, an adaptive MPC demonstrated reduced variability in performance under changing conditions [40] .

Another interesting example of MPC control of an SCR system was published in [37] . In this work, a linearized state-space SCR model was used in a standard unconstrained GPC-type formulation with $\mathrm{NO}_{x}$ efficiency, $\mathrm{NH}_{3}$ slip, and urea dosing as controlled variable targets in the cost function, in addition to the urea input increment penalty term.

\section{Adaptive Control}

Several SCR control designs for automotive applications have been proposed in recent years that use adaptive control [4144]. This can be considered a variation of a nonlinear estimator, but the analysis and design is significantly different. The uncertainly is addressed in the controller, not in the estimator, and usually a global stability analysis is performed for the design.

For instance, [19] proposed a closed loop PI controller, based on real time $\mathrm{NH} 3$ surface coverage computations, and using $\mathrm{NH} 3$ sensor feedback. The advantage of adaptive control schemes is that they can reduce the mismatch between the model and the actual system behavior by adjusting the model parameters. An overview of further adaptive approaches can be found in Table 7.

Table 7 - Examples of adaptive control techniques used in SCR system

\begin{tabular}{|c|c|c|c|c|}
\hline Ref & Controller & Model & $\begin{array}{l}\text { Control } \\
\text { Input }\end{array}$ & Control Output \\
\hline [44] & Adaptive & $\begin{array}{l}2^{\text {nd }} \text {-order } \\
\text { dynamic } \\
\text { system }\end{array}$ & $\begin{array}{l}\text { Catalyst } \\
\text { temperature }\end{array}$ & $\mathrm{NO} / \mathrm{NO}_{2}$ ratio \\
\hline [40] & $\begin{array}{l}\text { Adaptive } \\
\text { MPC }\end{array}$ & $\begin{array}{l}1^{\text {st }} \text {-order on- } \\
\text { line } \\
\text { linearization }\end{array}$ & $\begin{array}{l}\text { Molar ratio } \\
\text { of gaseous } \\
\mathrm{NH}_{3} \text { to } \mathrm{NO}_{x}\end{array}$ & $\begin{array}{l}\mathrm{NO}_{x} \text { conversion, } \\
\text { back-off } \mathrm{NH}_{3} \text { slip } \\
\text { constraint }\end{array}$ \\
\hline [37] & MPC & $\begin{array}{l}\text { Fourth- } \\
\text { order 1-D }\end{array}$ & $\begin{array}{l}\text { Injection } \\
\text { rate }\end{array}$ & $\begin{array}{l}\mathrm{NO}_{x} \text { conversion, } \\
\mathrm{NH}_{3} \text { slip, injection } \\
\text { rate }\end{array}$ \\
\hline [43] & Adaptive & $\begin{array}{l}0 \text {-D control- } \\
\text { oriented }\end{array}$ & $\begin{array}{l}\text { Injection } \\
\text { rate }\end{array}$ & $\begin{array}{l}\mathrm{NH}_{3} \text { storage }\left(\mathrm{NH}_{3}\right. \\
\text { coverage ratio) }\end{array}$ \\
\hline$[2$ & Adaptive PI & 1-D model & $\begin{array}{l}\text { Injection } \\
\text { rate }\end{array}$ & $\mathrm{NH}_{3}$ slip/coverage \\
\hline [19] & Adaptive & 1-D model & $\begin{array}{l}\text { Injection } \\
\text { rate }\end{array}$ & $\mathrm{NH}_{3}$ slip/coverage \\
\hline [42] & Adaptive & 1-D model & $\begin{array}{l}\text { Injection } \\
\text { rate }\end{array}$ & $\mathrm{NH}_{3}$ slip/coverage \\
\hline$[1$ & Adaptive & $1^{\text {st }}$ order & $\begin{array}{l}\text { Injection } \\
\text { rate }\end{array}$ & $\mathrm{NH}_{3}$ slip/coverage \\
\hline 1] & MRAC & 2-D model & $\begin{array}{l}\text { Injection } \\
\text { rate }\end{array}$ & $\begin{array}{l}\text { Reduction in } \mathrm{NO}_{\mathrm{x}} \\
\text { mass flow }\end{array}$ \\
\hline
\end{tabular}

\section{Integrated Strategies}

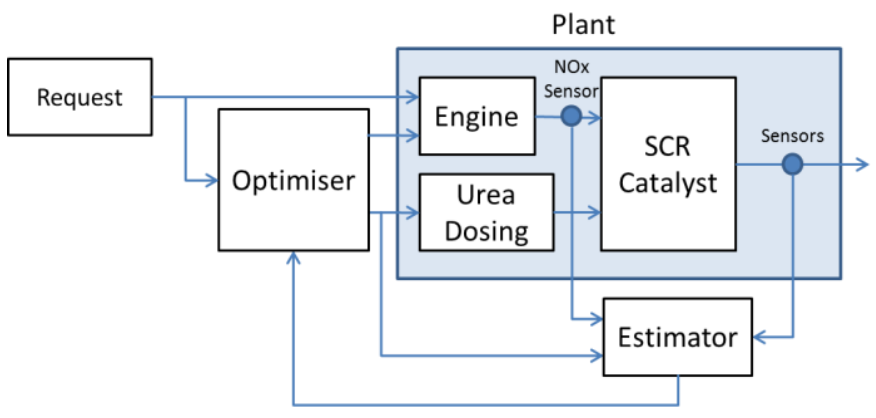

Figure 9 - An Integrated Control Structure

Many efforts have been made to simultaneously minimize both fuel consumption and emissions from combustion engines. High $\mathrm{NO}_{x}$ conversions within allowable $\mathrm{NH}_{3}$ slip limits are achieved by separately controlling both the engine and SCR systems in response to varying operating conditions. The growing complexity of these two systems, due in turn to the growing number of actuators, sensors, and sub-systems, make it a challenge to optimize the overall performance. The calibration effort using basic tuning methods increases exponentially with the number of actuators, which have been increasing significantly during the last decade. Therefore, maintaining separate controls for the engine and aftertreatment systems is no longer considered to be practical to meet future emission legislation, and an integrated control approach between the engine and SCR is considered to be the way forward. The key difference is that the engine is now considered as a part of the plant that is subject to control as shown in Figure 9.

Research in this area of Integrated Emission Management strategies is still in the development phase and only limited publications on the interaction between engine and aftertreatment control systems are found in the literature [45].

An example of such a strategy is presented by [46].The structure of the proposed concept is shown in Figure 10 below. The proposed strategy deployed a supervisory controller that would aim at satisfying the commanded torque by determining the optimal combination of control moves originating from the sub-controller level. To obtain an optimal balance between the control moves, an overall objective function is developed that is minimized by taking into accounts all the constraints and tradeoffs.

Another example of a combined heavy duty diesel engine and SCR system is presented by [45]. The proposed optimization method is based on a Sequential Quadratic Programming (SQP) algorithm and is claimed to have been successful in finding the instantaneous optimal balance between NOx reduction across the combined engine-SCR system and engine fuel economy. Recently, [47] presented a new design of the Integrated Emission Management strategy. The Integrated Emission Management functions as a supervisory controller, which determines the desired control settings for the different low-level controllers using online optimization. 


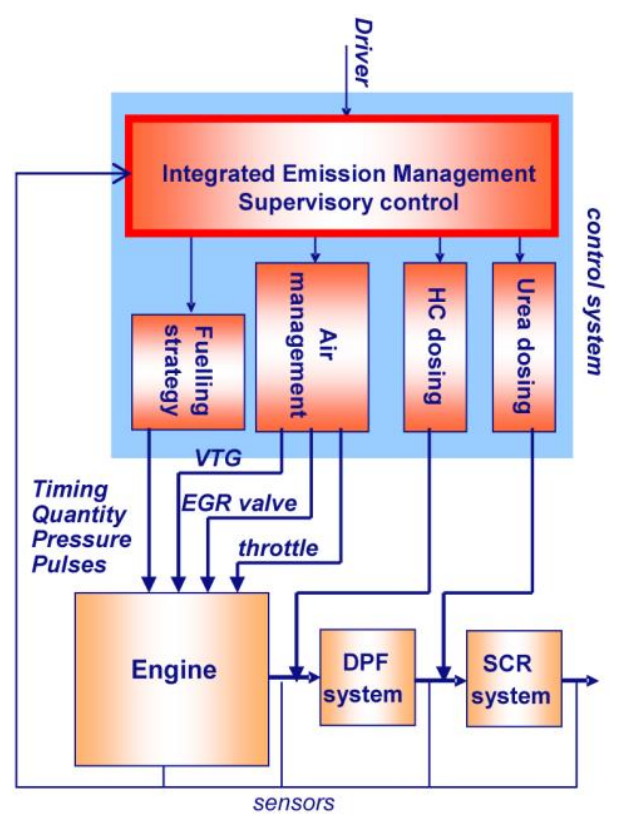

Figure 10 - Concept of an Integrated Emission Management Strategy [46]

The greatest potential for the proposed Integrated Emission Management framework is in exploring the trade-offs inherent in a closely connected system. Unlike the conventional approach of separately optimizing components of the overall system individually without consideration for the interactions, the global optimization approach can find a solution that is optimal for the whole system. This makes it a strong contender for the next phase in Euro-VI engine and aftertreatment calibration, with extension to other industrial applications.

\section{Summary / Conclusions}

In this paper, we have surveyed some recent advances in SCR systems control. Model developments have been reviewed and control problems based on these models have been discussed. Basic theories and methods for dealing with control problems of SCR systems were introduced and a few challenging issues were raised. Subsequently, we paid particular attention to control problems of nonlinear complex SCR systems with sensors.

The main conclusion is that sensor information is critical to address the SCR control problem. Good selection of sensors and sensible sensor placement can help to mitigate some of the control issues. Still, basic methods such as open loop control or PID control struggle with the complex non-linear dynamics, especially at high conversion. Therefore non-linear methods are indicated especially for the state estimation problem.

Different ways of framing the system can also have a huge impact on system performance. The most important choice is whether the catalyst temperature is controller or not, which is usually achieved via adjustments in the air and fuel system of the engine.

Finally, powerful control methods such as MPC are very attractive for this application, especially for an integrated Page 9 of 12 control approach. MPC methods deals directly with multivariable dynamics and multiple (potentially conflicting) objectives and constraints such as legislated emissions targets, and so can accurately predict and avoid undesirable situations such as $\mathrm{NH}_{3}$ slip whilst providing near-optimal $\mathrm{NO}_{x}$ conversion. Existing proposed formulations have so far avoided on-line constrained optimizations because of the associated computational burden, but this may change if more computational power becomes easily available.

\section{References}

[1] Chatterjee D., Burkhardt T., Rappe T., Güthenke A., et al., "Numerical simulation of DOC DPF SCR systems: DOC influence on SCR performance," SAE International Journal of Fuels and Lubricants 1(1):440-451, 2009.

[2] Nieuwstadt M. and Upadhyay D., "Control of Urea SCR Systems for US Diesel Applications," Oil \& Gas Science and Technology-Revue d'IFP Energies nouvelles 66(4):655-665, 2011.

[3] Harder H., Brugger M., and Brück R., "Future SCR NOX Aftertreatment Systems for Euro 6,"

http://www.emitec.com/fileadmin/user upload/Bibliothek/Vortra ege/20110127 SCR EU 6 Stuttgart Harder et.pdf, 2013.

[4] Akifumi Kawakami, Takashi Mizutani, Yukinari Shibagaki, et al. , "High Porosity DPF Design for Integrated SCR Functions", SAE Technical Paper 2012-01-0843, 2012, doi:10.4271/201201-0843.

[5] David Kittelson, Winthrop Watts, Andrew Walker and Martyn Twigg. , "On-Road Evaluation of an Integrated SCR and Continuously Regenerating Trap Exhaust System", SAE Technical Paper 2012-01-1088, 2012, doi:10.4271/2012-011088.

[6] Balaji Sukumar, Jianguo Dai, Asa Johansson, et al. "Modeling of Dual Layer Ammonia Slip Catalysts (ASC)", SAE Technical Paper 2012-01-1294, 2012, doi:10.4271/2012-011294.

[7] Jim Parks and Vitaly Prikhodko. , "Ammonia Production and Utilization in a Hybrid LNT+SCR System", SAE Technical Paper 2009-01-2739, 2009, doi:10.4271/2009-01-2739.

[8] E. Hünnekes, P. van der Heijden and J. Patchett. "Ammonia Oxidation Catalysts for Mobile SCR Systems", SAE Technical Paper 2006-01-0640, 2006, http://dx.doi.org/10.4271/2006-01-0640, doi:10.4271/2006-010640.

[9] Guzzella L.and Onder C., "Introduction to Modeling and Control of Internal Combustion Engine Systems," Springer, Berlin, ISBN 978-3-642-10775-7, 2010.

[10] Jing Hu, Yan-guang Zhao, Yun-long Zhang, et al. , "Development of Closed-loop Control Strategy for Urea-SCR Based on NOX Sensors", SAE Technical Paper 2011-01-1324, 2011, doi:10.4271/2011-01-1324. 
[11] M-F Hsieh and J. Wang. , "An Extended Kalman Filter for Ammonia Coverage Ratio and Capacity Estimations in the Application of Diesel Engine SCR Control and Onboard Diagnosis," American Control Conference 2010, 2010.

[12] Schär C.M., Onder C.H., and Geering H.P., "Control of an SCR catalytic converter system for a mobile heavy-duty application," IEEE Trans.Control Syst.Technol. 14(4):641-653, 2006.

[13] Willems F. and Cloudt R., "Experimental Demonstration of a New Model-Based SCR Control Strategy for Cleaner HeavyDuty Diesel Engines," Control Systems Technology, IEEE Transactions on 19(5):1305-1313, 2011.

[14] A. R. Ofoli. , "Experimental demonstration of ammonia storage and slip modeling with control for an SCR aftertreatment system," Industry Applications Society Annual Meeting (IAS), 2011 IEEE, 2011.

[15] De Rudder K., "Tier 4 High Efficiency SCR for Agricultural Applications," SAE Int.J.Commer.Veh. 5(1):386-394, 2012.

[16] John N. Chi. , "Control Challenges for Optimal NOx Conversion Efficiency from SCR Aftertreatment Systems", SAE Technical Paper 2009-01-0905, 2009, doi:10.4271/2009-010905.

[17] Frank Willems, Robert Cloudt, Edwin Van Den Eijnden, et al. , "Is Closed-Loop SCR Control Required to Meet Future Emission Targets ?", SAE Technical Paper 2007-01-1574, 2007, .

[18] Song Q. and Zhu G., "Model-Based, Closed-Loop Control of Urea Scr Exhaust Aftertreatment System for Diesel Engine,"(2002-01-0287), 2002.

[19] Herman A., Wu M., Cabush D., and Shost M., "Model Based Control of SCR Dosing and OBD Strategies with Feedback from NH3 Sensors," SAE Int.J.Fuels Lubr. 2(1):375385, 2009.

[20] Zhang S.M., Tian F., Ren G.F., and Yang L., "SCR control strategy based on ANNs and Fuzzy PID in a heavy-duty diesel engine," International Journal of Automotive Technology 13(5):693-699, 2012

[21] Hsieh M. and Wang J., "A Two-Cell Backstepping-Based Control Strategy for Diesel Engine Selective Catalytic Reduction Systems," Control Systems Technology, IEEE Transactions on 19(6):1504-1515, 2011.

[22] Ong C., Annaswamy A., Kolmanovsky I.V., Laing P., et al., "An Adaptive Proportional Integral Control of a Urea Selective Catalytic Reduction System based on System Identification Models," SAE Int.J.Fuels Lubr. 3(1):625-642, 2010.

[23] E. Schuster, C. E. Romero, Z. Yao, et al. , "Integrated nonmodel-based adaptive optimal control of SCR and APH systems at Cayuga Unit 1," 19th Annual Joint ISA
POWID/EPRI Controls and Instrumentation Conference and 52nd ISA POWID Symposium 2009, 2009.

[24] Mark Shost, John Noetzel, Ming-Cheng Wu, et al. , "Monitoring, Feedback and Control of Urea SCR Dosing Systems for NOx Reduction: Utilizing an Embedded Model and Ammonia Sensing", SAE Technical Paper 2008-01-1325, 2008, doi:10.4271/2008-01-1325.

[25] Radhamohan S. and Crane M.E., "Strategy for controlling NOx emissions and ammonia slip in an SCR system using a nonselective NOx/NH3," Patent WO2006000877A2, 5 Jan 2006.

[26] Buzanowski M.A., "Real-time Control for Zero Ammonia Slip setective Catalytic Reduction (SCR) System," US Patent 2004/0057889 A1, 2004.

[27] Buzanowski M.A., "Control for ammonia slip in selective catalytic reduction," US Patent 7166262, 23 Jan 2007.

[28] Zayan N.M., "SCR AMMONIA SLIP DETECTION," US Patent 13/267174, 2011.

[29] Binbin Shen, Fangping Yu, Huabiao Jin, Huayu Zhang and Qidou Wu. , "Applied research on diesel engine SCR system with the variable structure control theory," Electrical and Control Engineering (ICECE), 2011 International Conference on, 2011.

[30] Upadhyay D. and Van Niemvstadt M., "Model based analysis and control design of a Urea-SCR deNOx aftertreatment system," Journal of Dynamic Systems, Measurement and Control, Transactions of the ASME 128(3):737-741, 2006.

[31] Devarakonda M., Parker G., and Johnson J., "NOx CONTROL SYSTEMS AND METHODS FOR CONTROLLING NOx EMISSIONS," US Patent US8230677 B2, 2008.

[32] M-F Hsieh and J. Wang. , "Nonlinear Observer Designs for Diesel Engine Selective Catalytic Reduction (SCR) Ammonia Coverage Ratio Estimation," Proceedings of the IEEE Conference on Decision and Control 2009, 2009.

[33] M-F Hsieh and J. Wang. , "An extended Kalman filter for NOx sensor ammonia cross-sensitivity elimination in selective catalytic reduction applications," American Control Conference (ACC), 2010, 2010

[34] Guofeng Zhou, John Bagterp Jørgensen, Christophe Duwig and Jakob Kjøbsted Huusom. , "State Estimation in the Automotive SCR DeNOx Process," Advanced Control of Chemical Processes, 2012

[35] H. Surenahalli, G. Parker and J. Johnson. , "Extended Kalman Filter Estimator for $\mathrm{NH} 3$ Storage, NO, NO2 and NH3 Estimation in a SCR", SAE Technical Paper 2013-01-1581, 2013, doi:10.4271/2013-01-1581. 
[36] M. Meisami-Azad, J. Mohammadpour, K. M. Grigoriadis and M. P. Harold. , "An adaptive control strategy for urea-SCR aftertreatment system," American Control Conference (ACC), 2010, 2010.

[37] Chia-Jui Chiang, Chien-Liang Kuo, Chun-Chuan Huang and Jing-Yuh Lee. , "Model Predictive Control of SCR Aftertreatment System," 5th IEEE Conference on Industrial Electronics and Applications, 2010.

[38] Re L., Allgöwer F., Glielmo L., Guardiola C., et al., "Automotive model predictive control: models, methods and applications," Springer, 2010.

[39] Thomas L. McKinley and Andrew G. Alleyne. , "Model Predictive Control: A Unified Approach for Urea-Based SCR Systems", SAE Technical Paper 2010-01-1184, 2010, .

[40] McKinley T.L. and Alleyne A.G., "Adaptive Model Predictive Control of an SCR Catalytic Converter System for Automotive Applications," Control Systems Technology, IEEE Transactions on 20(6):1533-1547, 2012.

[41] J. N. Chi and H. F. M. Dacosta. , "Modeling and control of a urea-SCR after treatment system", SAE Technical Paper 2005-01-0966, 2005, doi:10.4271/2005-01-0966.

[42] Wang D.Y., Yao S., Shost M., and Yoo J., "Ammonia Sensor for Closed-Loop SCR Control," SAE

Int.J.Passeng.Cars - Electron.Electr.Syst 1(1):323-333, 2008.

[43] Hsieh M. and Wang J., "Adaptive and Efficient Ammonia Storage Distribution Control for a Two-Catalyst Selective Catalytic Reduction System," Journal of Dynamic Systems, Measurement, and Control 134(1):011012-011012, 2011.

[44] Chen P. and Wang J., "Nonlinear and Adaptive Control of NO/NO2 Ratio for Improving Selective Catalytic Reduction System Performance," Journal of the Franklin Institute 350(8):1992--2012, 2013.

[45] Claes Ericson, Björn Westerberg, Ingemar Odenbrand and Rolf Egnell. , "Characterisation and Model Based Optimization of a Complete Diesel Engine/SCR System", SAE Technical Paper 2009-01-0896, 2009, doi:10.4271/2009-01-0896.

[46] Cloudt R. and Willems F., "Integrated Emission Management strategy for cost-optimal engine-aftertreatment operation," SAE Int.J.Engines 4(1):1784-1797, 2011.

[47] P. Mentink, F. Willems, F. Kupper and E. Eijnden. "Experimental Demonstration of a Model-Based Control Design and Calibration Method for Cost Optimal Euro-VI EngineAftertreatment Operation", SAE Technical Paper 2013-011061, 2013, doi:10.4271/2013-01-1061.

[48] Louise Olsson, Hanna Sjövall and Richard Blint. A kinetic model for ammonia selective catalytic reduction over Cu-ZSM5812008.

Page 11 of 12
[49] Thomas L. McKinley and Andrew G. Alleyne. , "A Switched, Controls-Oriented SCR Catalyst Model Using OnLine Eigenvalue Estimation", SAE Technical Paper 2009-011284, 2009, doi:10.4271/2009-01-1284.

[50] M. Meisami-Azad, J. Mohammadpour, K. M. Grigoriadis and M. P. Harold. , "An adaptive control strategy for urea-SCR aftertreatment system," Proceedings of the 2010 American Control Conference, ACC 2010, 2010.

\section{Contact Information}

For further information, please contact Thomas Steffen, Lecturer in Control Engineering at Loughborough University. The recommended contact is via email t.steffen@lboro.ac.uk or t.steffen@ieee.org.

\section{Acknowledgments}

This literature overview was produced with the help of the Energy Technologies Institute (ETI), a public-private partnership between global energy and engineering companies and the UK Government. Special thanks go to our colleagues at Caterpillar and Johnson Matthey for their technical expertise.

\section{Definitions/Abbreviations}

AmOx - Ammonia Oxidation Catalyst
ANR - Ammonia NOx Ratio
ASC - Ammonia Slip Catalyst (same as AmOx)
DeNOx - remove NOx
DOC - Diesel Oxidation Catalyst
DPF - Diesel Particulate Filter
EGR - Exhaust Gas Recirculation
EKF - Extended Kalman Filter
ICE - Internal Combustion Engine
MPC - Model Predictive Control
NH ${ }_{3}$ - Ammonia
N2O - Nitrous Oxide (coll. laughing gas)
NO - Nitric Oxide, a clear gas
NOx - Nitrogen Oxide, specifically NO and NO 2
OBD - On-Board Diagnostics
PID - Proportional Integral Differential (Controller)
$\boldsymbol{R}_{\boldsymbol{u}}$ - universal gas constant
SCR - Selective Catalytic Reduction
T - Temperature
VGT/VTG - Variable Geometry Turbocharger


Page 12 of 12 